\title{
Family structure and risk behaviors: the role of the family meal in assessing likelihood of adolescent risk behaviors
}

This article was published in the following Dove Press journal:

Psychology Research and Behavior Management

15 February 2014

Number of times this article has been viewed

\section{Samantha Goldfarb \\ Will L Tarver \\ Bisakha Sen}

Department of Health Care Organization and Policy, School of Public Health, University of Alabama at Birmingham, Birmingham, AL, USA

Video abstract

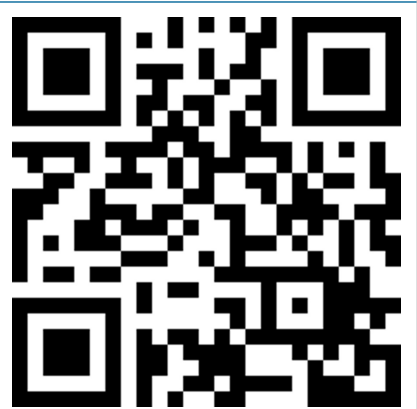

Point your SmartPhone at the code above. If you have a QR code reader the video abstract will appear. Or use: http://dvpr.es/laplXug
Correspondence: Bisakha Sen Department of Health Care Organization and Policy, School of Public Health, University of Alabama at Birmingham, Ryals Public Health Building, 1665 University Boulevard, Birmingham, AL 35294-0022, USA

Tel +l 2059758960

Email bsen@uab.edu
Background: Previous literature has asserted that family meals are a key protective factor for certain adolescent risk behaviors. It is suggested that the frequency of eating with the family is associated with better psychological well-being and a lower risk of substance use and delinquency. However, it is unclear whether there is evidence of causal links between family meals and adolescent health-risk behaviors.

Purpose: The purpose of this article is to review the empirical literature on family meals and adolescent health behaviors and outcomes in the US.

Data sources: A search was conducted in four academic databases: Social Sciences Full Text, Sociological Abstracts, PsycINFO ${ }^{\circledR}$, and PubMed/MEDLINE.

Study selection: We included studies that quantitatively estimated the relationship between family meals and health-risk behaviors.

Data extraction: Data were extracted on study sample, study design, family meal measurement, outcomes, empirical methods, findings, and major issues.

Data synthesis: Fourteen studies met the inclusion criteria for the review that measured the relationship between frequent family meals and various risk-behavior outcomes. The outcomes considered by most studies were alcohol use $(n=10)$, tobacco use $(n=9)$, and marijuana use $(n=6)$. Other outcomes included sexual activity $(n=2)$; depression, suicidal ideation, and suicide attempts $(n=4)$; violence and delinquency $(n=4)$; school-related issues $(n=2)$; and well-being $(n=5)$. The associations between family meals and the outcomes of interest were most likely to be statistically significant in unadjusted models or models controlling for basic family characteristics. Associations were less likely to be statistically significant when other measures of family connectedness were included. Relatively few analyses used sophisticated empirical techniques available to control for confounders in secondary data.

Conclusion: More research is required to establish whether or not the relationship between family dinners and risky adolescent behaviors is an artifact of underlying confounders. We recommend that researchers make more frequent use of sophisticated methods to reduce the problem of confounders in secondary data, and that the scope of adolescent problem behaviors also be further widened.

Keywords: family meals, adolescents, risk behaviors, review, study design, confounders

\section{Introduction}

Adolescence can be a time of turbulence, and primary challenges to adolescent health in the US are the health-risk behaviors that members of this age-group choose to engage in. ${ }^{1}$ Thus, there is substantial interest on the part of families, communities and policy makers in identifying effective protective factors against adolescent health-risk behaviors. 
In recent years, family meals have been heralded as a key protective factor for adolescents in the popular press, ${ }^{2,3}$ by policy groups, and by scientific researchers. There is a substantial literature that finds that eating with the family more frequently is associated with better psychological well-being ${ }^{4-8}$ and a lower risk of substance use and delinquency., ${ }^{4,5,79-13}$ Such findings have inspired community-, state-, and national-level programs that promote the concept of regular family meals, eg, the Family Day program initiated by the National Center on Addiction and Substance Abuse (http://www.casafamilyday.org). ${ }^{11}$ Numerous mechanisms via which family meals can improve adolescent well-being have been posited. For example, family meals may give adolescents and their parents the opportunity to converse, exchange ideas, discuss feelings, and thereby reinforce familial bonds..$^{14,15}$ Conversations at the dinner table may also give parents the opportunity to learn what is going on in their children's lives. ${ }^{11}$ Family meals might also facilitate parental monitoring and reduce time spent away from parental supervision..$^{10,14-16}$

At the same time, it must be recognized that families who select to have meals together may be different in other difficult-to-measure ways than families who do not. For example, families that eat together may have better interpersonal relationships or more vigilant parents to begin with, whereby family meals may merely serve as a proxy measure of those factors, and may not in themselves significantly impact any adolescent health or behavioral outcome. Moreover, adolescents are likely to have more autonomy than younger children in deciding whether to participate in family meals. Hence, it may be that adolescents who are well adjusted and less prone to delinquent behaviors are the ones who eat more frequently with their families. Thus, it is important to consider adjusting for these factors using the best available empirical methods, so as to better assess whether family meals, ceteris paribus, protect against adolescent risk behaviors.

For this article, we did a qualitative systematic review of the empirical literature on family meals and adolescent health behaviors and outcomes in the US. Our purpose was to inform on which risk behaviors are most frequently looked at in the literature, how rigorously potential confounders were adjusted for, and how frequently statistically significant associations were detected between family meals and the outcome of interest.

Specifically, we considered quantitative studies where the primary "treatment" of interest was family meals (including breakfast, lunch, or dinner), and the outcome of interest was an adolescent risk behavior. While the age range of adolescence often varies in definition, for this review we include studies whose participants were anywhere between the ages of 11 and 18 years. ${ }^{17}$ The range of risky behaviors encompasses substance use, sexual activity, violence and delinquency, school performance, depression and suicide ideation, general risky behaviors, and well-being, but for the purposes of this review we exclude outcomes related to obesity, dieting patterns, or eating disorders. We summarize our findings, and report on the empirical methods used, with specific focus on whether available empirical methods to minimize the effects of confounders in observational data were used.

\section{Materials and methods \\ Search strategy}

We followed all of the recommendations of the Preferred Reporting Items for Systematic Reviews and Meta-Analyses (PRISMA) statement that were applicable to our study. ${ }^{18}$ Computer-based searches were conducted of the following academic databases: 1) Social Sciences Full Text (coverage: 1983 to present); 2) Sociological Abstracts (coverage: 1952 to present); 3) PsycINFO ${ }^{\circledR}$ (coverage: 1806 to present); and 4) PubMed/MEDLINE (coverage: 1946 to present). We used various combinations of keywords relating to family meals and selected risk-behavior outcomes to maximize search results. We searched each database with search terms to identify articles that suggested a family interaction (ie, "family," "parents," "mother," "father" in combination with "adolescence," "adolescent," "teen," "young adult," "juvenile," "youth"). To capture this family interaction in the context of the family meal, additional keywords were used (ie, "meals," "breakfast," "lunch," "dinner," "eating," "dining"). In addition, outcomes were captured using variations of such keywords as "risky behaviors," "depression," "violence," "delinquency," "unintentional injury," "suicide," "drug use," "substance use," "alcohol use," "tobacco use," "smoking," "drinking," "sexual behaviors," "unintended pregnancy," "sexually transmitted diseases," "school," and "well-being." A complete list of search terms can be found in Table 1.

\section{Study selection}

We conducted a systematic search for studies that reported quantitative empirical data assessing the relationship between family meals and risk behaviors in adolescents published between January 1990 and September 2013. Additional inclusion criteria included articles published in the English language and conducted in the US. Only studies conducted in the US were included. This is because perceptions about 
Table I Keywords used to search the literature on family meals and adolescent risk behaviors

Sociological Abstracts/Social Sciences Full Text/PsycINFO ${ }^{\circledR}$ PubMed/MEDLINE 1990-20I3

\begin{tabular}{|c|c|c|c|}
\hline Family and & Meal and & Adolescent* and & Risk* behavior* \\
\hline Parents & Breakfast & Teen* & Risk* behaviour* \\
\hline Mother & Lunch & Young adult* & Problem behaviour \\
\hline \multirow[t]{30}{*}{ Father } & Dinner & Juvenile & Problem behavior \\
\hline & Eating & Youth & Depression \\
\hline & Dining & & Violence \\
\hline & & & Delinquency \\
\hline & & & Unintentional injury* \\
\hline & & & Suicide \\
\hline & & & Self injury \\
\hline & & & Self-injury \\
\hline & & & Drug* \\
\hline & & & Substance* \\
\hline & & & Alcohol \\
\hline & & & Tobacco \\
\hline & & & Smoking \\
\hline & & & Drinking \\
\hline & & & Sexual behaviors \\
\hline & & & Sexual behaviours \\
\hline & & & Sexual initiation \\
\hline & & & Sexual debut \\
\hline & & & Unintended pregnancy \\
\hline & & & Unplanned pregnancy \\
\hline & & & Sexually transmitted \\
\hline & & & disease* \\
\hline & & & STD* \\
\hline & & & HIV \\
\hline & & & AIDS \\
\hline & & & School \\
\hline & & & Grades \\
\hline & & & Student dropout* \\
\hline & & & Well being \\
\hline & & & Well-being \\
\hline
\end{tabular}

Note: *Keyword truncation.

Abbreviations: STD, sexually transmitted disease; HIV, human immunodeficiency virus; AIDS, acquired immunodeficiency syndrome.

what adolescent "risk behaviors" are may differ across countries, eg, anecdotal evidence suggests that children in France are often permitted to consume wine by their parents and guardians, and moderate alcohol consumption is not viewed as a "problem" per se. ${ }^{19}$ We wanted to ensure some consistency in defining problem behaviors. Additionally, there may be certain different cultural connotations about what occurs during family meals, such as the nature of the conversation, which may differentially moderate the relationship between family meals and problem behaviors for different cultures. Hence, we took the approach of confining our studies to the US.

In order to determine study eligibility, two reviewers (SG and WT) independently assessed the titles and abstracts of all citations identified in the search for possible inclusion. Any differences between reviewers were resolved by consensus, and when necessary, discussion with the senior author (BS). For the studies that met the inclusion criteria, the full text was retrieved and obtained for independent assessment. The primary reasons for exclusion from this review were that the studies were nonempirical, conducted outside the US, or not relevant to our review. Examples of articles identified as not relevant to our review included articles that did not did not use an adolescent risk behavior as an outcome, did not capture family involvement in terms of family mealtime, and articles where family meals were the outcome rather than the main covariate of interest.

Agreement between reviewers was assessed with Cohen's $\kappa$ coefficient. ${ }^{20}$ This statistic measures agreement on a scale of 0 to 1 , where 0 represents agreement or disagreement simply by chance and 1 represents perfect agreement. ${ }^{21}$ Cohen's $\kappa$ coefficient was calculated using GraphPad (GraphPad Software, La Jolla, CA, USA). ${ }^{22}$ Fourteen studies were identified that met our inclusion criteria..$^{5-10,12,23-29}$

\section{Data extraction}

The full text of each article that met our inclusion criteria was reviewed. Data extraction and entry was performed using a serial review process. The primary reviewer (SG) extracted data from each article and entered the information into a standardized database under the major headings of Sample, Study design, Family meals measurement, Outcomes, Empirical methods, Findings, and Major issues. The extracted data were reviewed for accuracy by the second reviewer (WT).

\section{Results}

Figure 1 illustrates the literature review and search process used to identify the 14 studies included in this review from an initial yield of 1,077 citations. The initial search yielded 791 studies after removing duplicate citations. After applying the restrictions for inclusion, 747 studies were excluded upon title review, 28 studies were excluded upon abstract review, and two studies were excluded upon full-text article review. The two reviewers achieved good agreement in the initial review of titles for inclusion $(\kappa=0.79,95 \%$ confidence interval [CI] 0.68-0.91), very good agreement on the review of abstracts for inclusion ( $\kappa=0.87,95 \%$ CI: $0.73-1.00)$, and perfect agreement on the review of full-text articles $(\kappa=1.00$, 95\% CI: 1.00-1.00).

We summarize the final list of studies, data sets used, measures of family meals, outcomes, empirical approaches, and significant results in Table 2. 


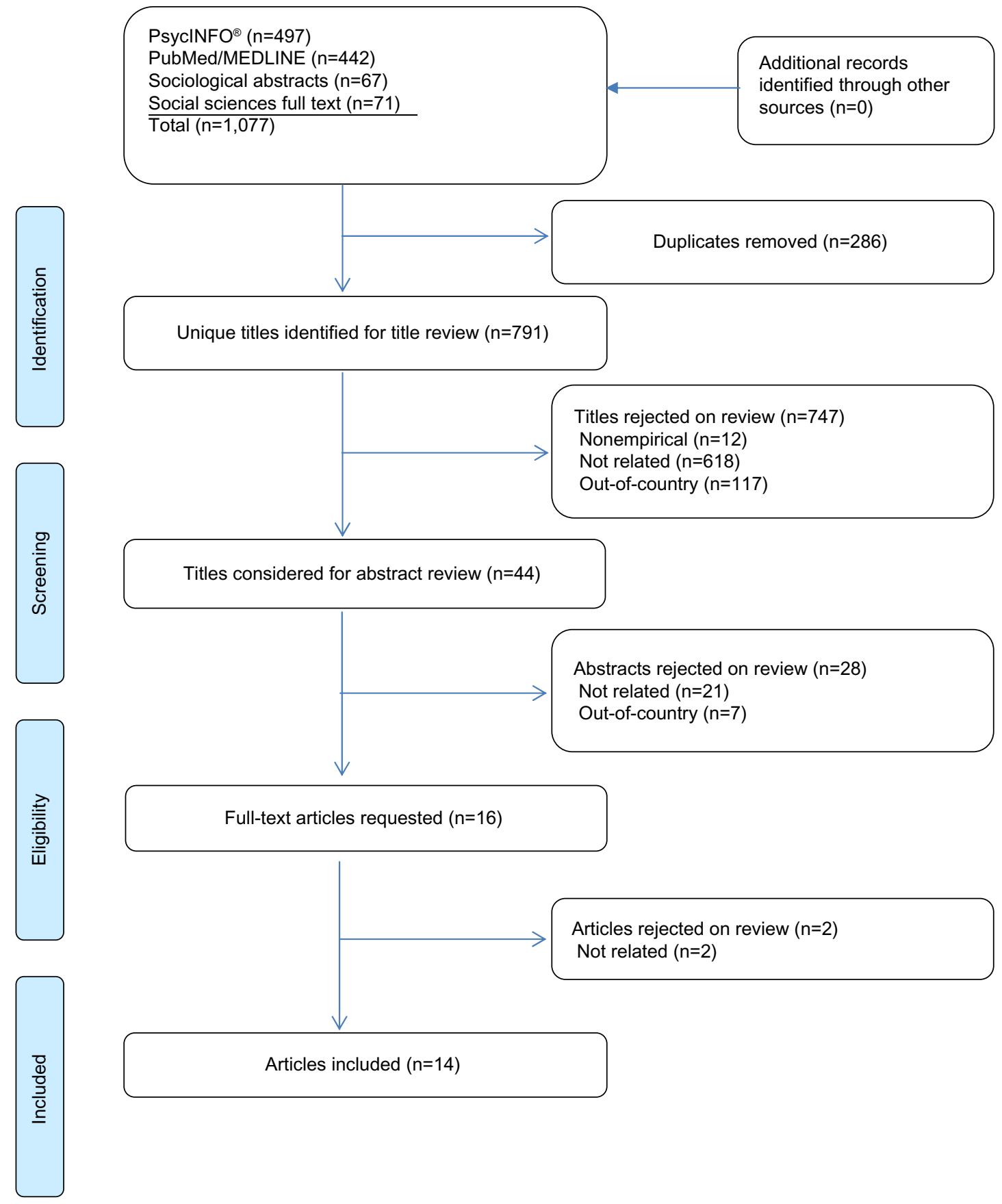

Figure I Family structure and risk behaviors: the role of the family meal in assessing likelihood of adolescent risk behaviors flowchart.

\section{Family meal measurement}

The main covariate of interest in the final list of studies was family meals. Four studies measured the family meal variable continuously, ${ }^{8,10,28,29}$ six measured it categorically, ${ }^{5,7,9,12,23,24}$ two measured it both ways, ${ }^{6,25}$ and two measured it experimentally. ${ }^{26,27}$ Of these studies, eight asked about the frequency of family dinner in particular, ${ }^{6-8,10,12,24,25,28}$ five asked about the frequency of family meals in general, ${ }^{5,9,23,26,27}$ and one asked about the priority of family meals. ${ }^{29}$ Of the studies that categorically recoded the family meal/dinner variable, five or more meals was typically considered to be "regular" or "frequent."',7,9

\section{Outcomes}

As can be seen from Table 2, ten studies examined the relationship between frequent family meals (FFM) and adolescent alcohol use; nine studies examined the relationship between FFM and adolescent tobacco use; six studies 
examined the relationship between FFM and adolescent marijuana use, and two of those studies additionally examined the relationship between FFM and other illicit drug use, including cocaine products, inhalants, and other illegal drugs. Substantial variation existed in how the outcomes were measured. For example, three studies measured alcohol use in the past year, four measured use in the past month or two weeks, and two had general questions related to alcohol initiation, frequency, stage of uptake, and/or binge drinking. One longitudinal study asked about initiation and frequency of use since the last interview and in the last year. Similarly, three studies measured tobacco use in the past year, four measured use in the past month or daily, one used a general question related to tobacco initiation and frequency, and one longitudinal study asked about initiation and frequency of use since the last interview and in the past year.

Three studies measured the association between FFM and adolescent sexual activity. One examined sexual initiation, and one study examined if the respondent had engaged in frequent sexual activity (three or more times). Five studies investigated the relationship between FFM and adolescent depression and/or suicide ideation/attempts. Three studies measured depressive symptoms in the past week or month, and two measured both depressive symptoms and suicide ideation or attempts. Six studies measured the impact of family meals on measures related to adolescent well-being. Three studies measured issues related to positive identity (eg, self-esteem, sense of purpose, positive view of personal future), one measured perceived stress, and two measured several aspects of emotional well-being (eg, "positive affect" or feelings of well-being, "negative affect" or feelings of distress/stress, and "engagement" or feelings of enjoyment in activities). Four studies addressed FFM and adolescent violence and delinquency, which included acts of aggression/ violence (eg, fighting, carrying a weapon, causing physical harm) and delinquency/antisocial behavior (eg, shoplifting, stealing, vandalism, trouble with law-enforcement officials). Finally, two studies considered the relationship between FFM and school-related issues, with one considering academic performance (eg, most common grade received) and the other considering school problems (eg, less than $\mathrm{C}$ grade point average, skipping school).

\section{Empirical approach and significant findings}

In Table 3, we summarize the frequency with which the association between FFM and each outcome of interest was analyzed. If a paper included several analyses, eg, using different measures of FFM or the outcome, included both cross-sectional and longitudinal analysis, or stratified analysis by sex or other characteristics, then each of those is counted as a separate analysis. We also summarized the number of times the relationship was estimated using unadjusted models, using models that controlled for standard demographic and family characteristics, using models that additionally controlled for other measures of family/parental connectedness, and using models that used advanced empirical techniques to minimize bias arising from confounders. The standard demographic characteristics typically included the adolescent's sex, race/ethnicity, age and/or school grade, family structure, and one or more indicators of socioeconomic status, such as parental education, household income, or eligibility for public assistance. Models that adjusted for family/parental connectedness took various approaches, eg, Eisenberg et $\mathrm{al}^{5,9}$ controlled for family connectedness using four survey items on adolescent perceptions of how much each parent cared for them, and how well they could talk to each parent about problems; Pearson et $\mathrm{al}^{28}$ controlled for quality of parent-child relationships, other shared family activities, and parent-reported communications with the adolescent about sex; Fulkerson et $\mathrm{al}^{7}$ controlled for family support, positive family communications, parental involvement in school, family rules and boundaries, and positive adult role models. Sen ${ }^{10}$ controlled for other family activities, and parental awareness of the adolescent's friends, teachers, school activities, and who the adolescent is with when not at home; Musick and Meier ${ }^{8}$ controlled for global family relationship quality, parent-child family relationship quality, other activities with parents, arguments with parents, and the extent of parental control. Hoffmann and Warnick ${ }^{25}$ used "balanced" control and treatment samples on parent-child relationships based on a 16-question scale, and the same parental awareness questions as Sen. ${ }^{10}$

Finally, with respect to more advanced techniques for minimizing the problem of confounders, Hoffmann and Warnick ${ }^{25}$ used a propensity score-matching approach, and balanced their treatment and control samples by using parentchild relationship quality, parental awareness, composite scores to measure the quality of the home and neighborhood environment, and the time the adolescent spends on other activities like homework, reading for pleasure, and television viewing. Sen ${ }^{10}$ used the frequency of family dinners in year $t+1$ as a proxy variable for the adolescent's propensity to spend mealtimes with families. Musick and Meier ${ }^{8}$ estimated "first-difference" models utilizing the difference in outcomes as well as in family dinner frequency between two waves 
Table 2 Study details and main effects of family meals on adolescent risk-behavior outcomes

\begin{tabular}{llll}
\hline Author & Data & Family meal variable & Outcome \\
\hline${\text { Eisenberg et a }{ }^{5}}^{\text {Project EAT (Eating Among }}$ & "During the past 7 days, how many times did all & (I) Academic performance \\
& Teens) $^{\mathrm{a}}$ & or most of your family living in your house eat a & (2) Past-year substance use \\
& meal together?" & (3) Self-esteem \\
& Response categories: never; I-2 times; 3-4 times; & (4) Depressive symptoms \\
& $5-6$ times; 7 times; more than 7 times & (5) Suicidal ideation/suicide \\
& & attempts
\end{tabular}

Eisenberg et al ${ }^{9} \quad$ Project EAT-II (Eating Among Teens) ${ }^{\mathrm{b}}$

$\begin{array}{ll}\text { Fisher et al }^{12} & \begin{array}{l}\text { Growing Up Today Study } \\ (\text { GUTS })^{c}\end{array}\end{array}$

Franko et $\mathrm{al}^{23} \quad$ National Heart, Lung, and Blood Institute Growth and Health Study (NGHS), girls only
"During the past 7 days, how many times did all or most of your family living in your house eat a meal together?"

Response categories: never; I-2 times; 3-4 times; 5-6 times; 7 times; more than 7 times

"How often do you sit down with other members of your family to eat dinner or supper?"

Response categories: never or some days compared to I) most days and 2) every day "How often do you eat with your parents?" Response categories: never or almost never; sometimes; usually/always
Past-year substance use

(I) Initiation of alcohol use

(2) Binge drinking (among initiators)

(3) Stage of alcohol uptake

(I) Perceived stress

(2) Past-month alcohol use

(3) Past-month cigarette use

(4) Daily cigarette use

\begin{tabular}{|c|c|c|c|}
\hline Fulkerson et $\mathrm{al}^{6}$ & $\begin{array}{l}\text { Team COOL (Controlling } \\
\text { Overweight and Obesity } \\
\text { for Life) }\end{array}$ & $\begin{array}{l}\text { "During the past week, how many days did all or most } \\
\text { of the people you live with eat dinner together?" } \\
\text { Response categories (continuous): never; I day; ...; } \\
6 \text { days; every day (categorical): never; I-4 days; } \\
5-7 \text { days }\end{array}$ & $\begin{array}{l}\text { (I) Past-year substance use } \\
\text { (2) Depressive symptoms }\end{array}$ \\
\hline Fulkerson et $\mathrm{a}^{29}$ & $\begin{array}{l}\text { Project EAT (Eating Among } \\
\text { Teens) })^{\mathrm{a}}\end{array}$ & $\begin{array}{l}\text { Priority of Family Meal Scale ( } 5 \text { items), with higher } \\
\text { scores indicating high priority of shared meals }\end{array}$ & $\begin{array}{l}\text { (1) Depressed mood } \\
\text { (2) Self-esteem } \#\end{array}$ \\
\hline Fulkerson et $\mathrm{al}^{7}$ & $\begin{array}{l}\text { Nationwide } \\
\text { (nonrepresentative) study }\end{array}$ & $\begin{array}{l}\text { "In an average week, how many times do all of the } \\
\text { people in your family who live with you eat dinner } \\
\text { together?" } \\
\text { Response categories (recoded): } 0-1 \text { time; } 2-4 \text { times; } \\
5-7 \text { times }\end{array}$ & $\begin{array}{l}\text { (I) Alcohol use } \\
\text { (2) Tobacco use } \\
\text { (3) Illicit drug use } \\
\text { (4) Sexual intercourse } \\
\text { (5) Depression/suicide } \\
\text { (6) Antisocial behavior } \\
\text { (7) Violence } \\
\text { (8) School problems } \\
\text { (9) Self-esteem } \\
\text { (10) Sense of purpose } \\
\text { (II) Positive view/personal future }\end{array}$ \\
\hline
\end{tabular}




\begin{tabular}{l}
\hline Empirical approach \\
\hline Logistic regression, \\
stratified by sex
\end{tabular}

Logistic regression, stratified by sex

Logistic regression, stratified by sex

Chi-square analysis

Mixed-model logistic and linear regressions

Hierarchical multiple regression, stratified by sex

Logistic regression
Cross-sectional, adjusted for basic

demographics*, family connectedness ${ }^{\wedge}$, and related outcome variables (if applicable)

Longitudinal, adjusted for basic demographics* and family connectedness ${ }^{\wedge}$

Prospective cohort study, adjusted for individual*, family ${ }^{\wedge}$, and social ${ }^{+}$variables

Longitudinal, adjusted for basic demographics*

Cross-sectional, adjusted for basic demographics*, included "school" as a random effect

Cross-sectional, adjusted for basic demographics* and family connectedness^

Cross-sectional, adjusted for basic demographics* and family connectedness^
Significant findings

Per-unit increase in FMF

(I) Academic performance Female aOR: $0.92 ; \mathrm{Cl}$ : 0.87-0.98

(2) Alcohol use Female aOR: 0.83 ; Cl: 0.77-0.90 Male aOR: $0.94 ; \mathrm{Cl}: 0.87-1.02$

(2) Cigarette use Male aOR: 0.90; Cl: 0.83-0.98

(2) Marijuana use Female aOR: 0.84; Cl: 0.76-0.94

(4) High depressive symptoms Female aOR: 0.92; Cl: 0.86-0.98

Regular ( $5+/$ week) family meals at baseline Alcohol use (at 5-year follow-up): Female aOR: 0.52; Cl: 0.30-0.9। Cigarette use (at 5-year follow-up): Female aOR: 0.48; Cl: 0.29-0.8I Marijuana use (at 5 -year follow-up): Female aOR: 0.49 ; $\mathrm{Cl}$ : 0.25-0.95 Family dinner every day vs never or some days

(I) Alcohol initiation at I-year follow-up Female aOR: 0.66 ; Cl: 0.50-0.87

FMF (mean/SD)

(I) Stress score (years 5/6), $P=0.03$

Never/almost never: $23.56(0.52)$

Sometimes: $24.35(0.24)$ Usually/always: $23.4 \mathrm{I}(0.26)$

(I) Stress score (year I0), $P=0.007$ Never/almost never: $23.36(0.54)$

Sometimes: $23.20(0.24)$

Usually/always: $22.08(0.26)$

FMF (\% outcome)

(3) Past-month cigarette use (years 5/6), $P=0.05$ Never/almost never: 13.5

Sometimes: 13.1

Usually/always: 9.9

FDF (mean/SD)

(2) Depressive symptom score, $P<0.05$

Never: 18.7 (0.74)

I-5 days: $17.4(0.78)$

6-7 days: $16.3(0.52)$

High priority of family meal

(I) Depressed mood Male $\beta=-0.14, P<0.01$

(2) Self-esteem Male $\beta=0.09, P<0.05$

5+ Family dinners/week

(I) Alcohol use aOR: 0.57; Cl: 0.52-0.62

(2) Tobacco use aOR: 0.48; Cl: 0.43-0.53

(3) Illicit drug use aOR: 0.46; Cl: 0.42-0.5I

(4) Sexual intercourse aOR: 0.42; Cl: 0.38-0.47

(5) Depression/suicide aOR: $0.60 ; \mathrm{Cl}: 0.54-0.65$ 
Table 2 (Continued)

\begin{tabular}{llll}
\hline Author & Data & Family meal variable & Outcome \\
\hline $\begin{array}{l}\text { Fulkerson et } \mathrm{al}^{7} \\
\text { (Continued) }\end{array}$ & & &
\end{tabular}

\begin{tabular}{|c|c|}
\hline Griffin et $\mathrm{al}^{24}$ & $\begin{array}{l}\text { New York City public } \\
\text { school studys }\end{array}$ \\
\hline Hoffmann and & National Longitudinal Study \\
\hline Warnick $^{25}$ & of Youth (NLSY) ${ }^{\mathrm{h}}$ \\
\hline
\end{tabular}

Musick and National Longitudinal Survey Meier $^{8} \quad$ of Adolescent Health (Add Health) ${ }^{\mathrm{i}}$

Offer $^{26}$

Sloan 500 Family Study
"How often does the family eat dinner together?" (parent report) Response categories: 6-point scale from never (0) to every day (5) "In a typical week, how many days from 0 to 7 do you eat dinner with your family?"

Response categories (binary): 0-4 days vs 5-7 days Response categories (categorical): 0-2 days;

3-5 days; 6-7 days

Response categories (continuous): 0 days;

I day; ...; 7 days

"On how many of the past 7 days was at least one of your parents in the room with you while you ate your evening meal?" Response categories: no days; I day; ...; 7 days

Per experience sampling method (ESM), respondents report on current activities, specifically if they were eating meals, and if so, who they were with (mom, dad, both parents)
(I) Lifetime substance use

(2) Interpersonal aggression

(3) Delinquency

(I) Past-month alcohol use

(2) Past-month tobacco use

(3) Past-month marijuana use
(I) Depressive symptoms

(2) Substance use (ever, since last interview, in past year)

(3) Delinquency

(I) Positive affect

(2) Engagement

(3) Negative affect

(4) Stress
Per ESM, respondents report on current activities, specifically if they were eating meals, and if so, who they were with (mom, dad, both parents)
(I) Positive affect

(2) Engagement

(3) Negative affect

(4) Stress 


\section{Empirical approach}

Hierarchical multiple regression

Multinomial regression models

Multivariate regression models

Hierarchal linear models

Hierarchal linear models, stratified by meal with mom only, dad only, or both parents
Cross-sectional, adjusted for basic demographics* and family connectedness ${ }^{\wedge}$

Longitudinal, adjusted for propensity score matching based on individual, family, and social characteristics ${ }^{+}$

Longitudinal, adjusted for basic demographics* and family connectedness ${ }^{\wedge}$, fixed effects to control for time-invariant individual-level heterogeneity Adjusted for basic demographics* and family connectedness ${ }^{\wedge}$

Adjusted for basic demographics* and family connectedness^
Significant findings

(6) Antisocial aOR: 0.63 ; $\mathrm{Cl}: 0.58-0.69$

(7) Violence aOR: $0.74 ; \mathrm{Cl}: 0.68-0.8$ I

(8) School problems aOR: 0.50; $\mathrm{Cl}: 0.44-0.55$

(9) Self-esteem aOR: I.4; Cl: I.27-I.49

(10) Sense of purpose aOR: I.5; Cl: I.37-I.6।

(II) Positive view/personal future aOR: I.3; Cl: I.23-I.46

Parent-reported dinner together

(2) Interpersonal aggression (5-point scale) $\beta=-0.18, P<0.01$

FDF (categorical)

6-7 dinners/week compared to

0-2 dinners/week:

(3) Marijuana use $\beta=-0.038, P<0.05$

FDF (continuous)

One-unit increase in family dinners/week:

(3) Marijuana use $\beta=-0.014, P<0.01$

FDF (fixed effects)

(I) Depressive symptoms $\beta=-0.005, P<0.05$

Mealtime with any/both parents

(I) Positive affect $\beta=0.16$, SE: 0.04

(2) Engagement $\beta=0.22$, SE: 0.05

(3) Negative affect $\beta=-0.13$, SE: 0.03

(4) Stress $\beta=-0.09$, SE: 0.03

Meal with mother only

(2) Engagement $\beta=0.17$, SE: 0.09

Meal with father only

(2) Engagement $\beta=0.17$, SE: 0.09

(3) Negative affect $\beta=-0.25$, SE: 0.05

(4) Stress $\beta=-0.15$, SE: 0.06

Meal with both parents

(I) Positive affect $\beta=0.18$, SE: 0.05

(2) Engagement $\beta=0.27$, SE: 0.07

(4) Stress $\beta=-0.16$, SE: 0.04 
Table 2 (Continued)

\begin{tabular}{|c|c|c|c|}
\hline Author & Data & Family meal variable & Outcome \\
\hline Pearson et $\mathrm{al}^{28}$ & $\begin{array}{l}\text { National Longitudinal Survey } \\
\text { of Adolescent Health (Add } \\
\text { Health)' }\end{array}$ & $\begin{array}{l}\text { "On how many of the past } 7 \text { days was at least one } \\
\text { of your parents in the room with you while you } \\
\text { ate your evening meal?" } \\
\text { Response categories: no days; I day; ...; } 7 \text { days }\end{array}$ & Sexual initiation \\
\hline $\operatorname{Sen}^{10}$ & $\begin{array}{l}\text { National Longitudinal Survey } \\
\text { of Youth (NLSY) }\end{array}$ & $\begin{array}{l}\text { "In a typical week, how many days from } 0 \text { to } 7 \text { do } \\
\text { you eat dinner with your family?" } \\
\text { Response categories: } 0 \text { days; I day; ...; } 7 \text { days }\end{array}$ & $\begin{array}{l}\text { (I) Smoking } \\
\text { (2) Alcohol consumption } \\
\text { (3) Binge drinking } \\
\text { (4) Marijuana use } \\
\text { (5) Engaging in physical violence } \\
\text { (6) Deliberately destroying others' } \\
\text { property } \\
\text { (7) Stealing } \\
\text { (8) Running away from home } \\
\text { (9) Belonging to a gang }\end{array}$ \\
\hline
\end{tabular}

Notes: aProject EAT was a survey administered to $3 \mathrm{I}$ public middle and high schools in ethnically and socioeconomically diverse communities in urban/suburban areas of Minneapolis/ St Paul. I,608 middle school and 3,074 high school students aged I I-18 years participated during the 1998-1999 school year. Fulkerson et al29 included only a subsample of participants

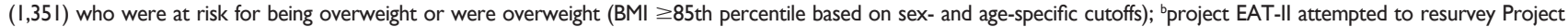
EAT-I sample of middle school students (grades 7 and 8, $n=1,608$ ) in Twin Cities, Minnesota during the 1998-1999 school year. Follow-up sample (346 male, 440 female) surveyed at two time points 5 years apart; 'GUTS is a prospective cohort study of mothers recruited in 1996 from the ongoing Nurses' Health Study who had children aged 9-14 years. Final sample is from follow-up questionnaire in 1998 and 1999: 3,283 girls and 2,228 boys; ${ }^{\mathrm{N} G H S}$ is a 10 -year longitudinal study of 2,379 black and white girls who were 9 or 10 years old at study entry in 1992. Participants were recruited from three study sites: University of California, Berkeley, University of Cincinnati/Cincinnati Children's Hospital Medical Center, and Westat/Group Health in Rockville, MD, USA. Girls were interviewed annually between study year I and study year 10; ${ }^{\mathrm{e}}$ eam COOL is a group randomized trial to evaluate a high school-based intervention to combat obesity by promoting physical activity and healthy eating. Four urban and two suburban alternative high schools in Minneapolis/St Paul metro area participated in 2006 ( $n=145$ students); 'nationwide survey of 99,642 sixth to twelfth grade students from public and alternative schools in 213 cities and 25 states across the US. Most students in the sample were Caucasian, from small towns with educated parents. This sample is not representative, because school districts self-selected to administer the surveys during the 1996-1997 academic year; 'survey of two New York City public middle school students. Sample included 228 sixth grade students. Participating parents were also interviewed by phone, and their responses were matched to their child's survey responses; 'NLSY is a nationally representative sample of adolescents aged I2-16 years $(\mathrm{n}=6,748)$ on December 31, 1996, coupled with a supplemental oversample of 2,236 black and Hispanic adolescents that are nationally representative of their respective race/ethnicity. Participants have been surveyed repeatedly since 1997, with a low attrition rate; 'add Health is a nationally representative sample of adolescents in grades 7-12 in 1994-1995 (wave I). Wave 2 was conducted in 1996 and wave 3 in 200I-2002. Combination of self-administered, in-school questionnaires and in-home interviews ( $n=13,84$ I); iSloan 500 Family Study is a nonrandom sample of dual-earner middle-class families with children, designed to collect in-depth information about daily experiences of family members at home, work, and school. Families recruited in 1999 and 2000 in eight urban and suburban communities across the US through local ads and posts at local schools. As a mixed-methods study, teenagers (aged I I-18 years) were asked to complete a survey and fill in a time diary using the ESM (alarm watches that signal [beeps] respondents during their waking hours for 7 consecutive days to report and evaluate their activities and emotions in a self-report questionnaire); "this study also measured other outcome variables, which included some of the following categories: dietary intake, eating disorder behavior, weight status, family support/involvement, peer influence, and school engagement; *basic demographics include most or all of the following: age/school level, race/ethnicity, socioeconomic status (family income, parent education/employment status, family eligibility for public assistance/free or reduced-cost school meals), family composition/structure, number of children in household, study site, and type/size of community; 'family connectedness includes one or more of the following: parental monitoring, parental caring, family support, family communication, family activities, family arguments, parental control, parent-child relationship, and parent involvement; 'social context variables include one or more of the following: peer substance use, own or willing to use an alcohol promotional item (API), talked about alcohol advertisement, Alcohol Expectancy Questionnaire - Adolescent score (propensity to initiate alcohol use), adolescent time use, and physical environment.

Abbreviations: aOR, adjusted odds ratio; $\mathrm{Cl}$, confidence interval; BMI, body mass index; FMF, family meal frequency; FDF, family dinner frequency; SE, standard error; ME, marginal effect. 


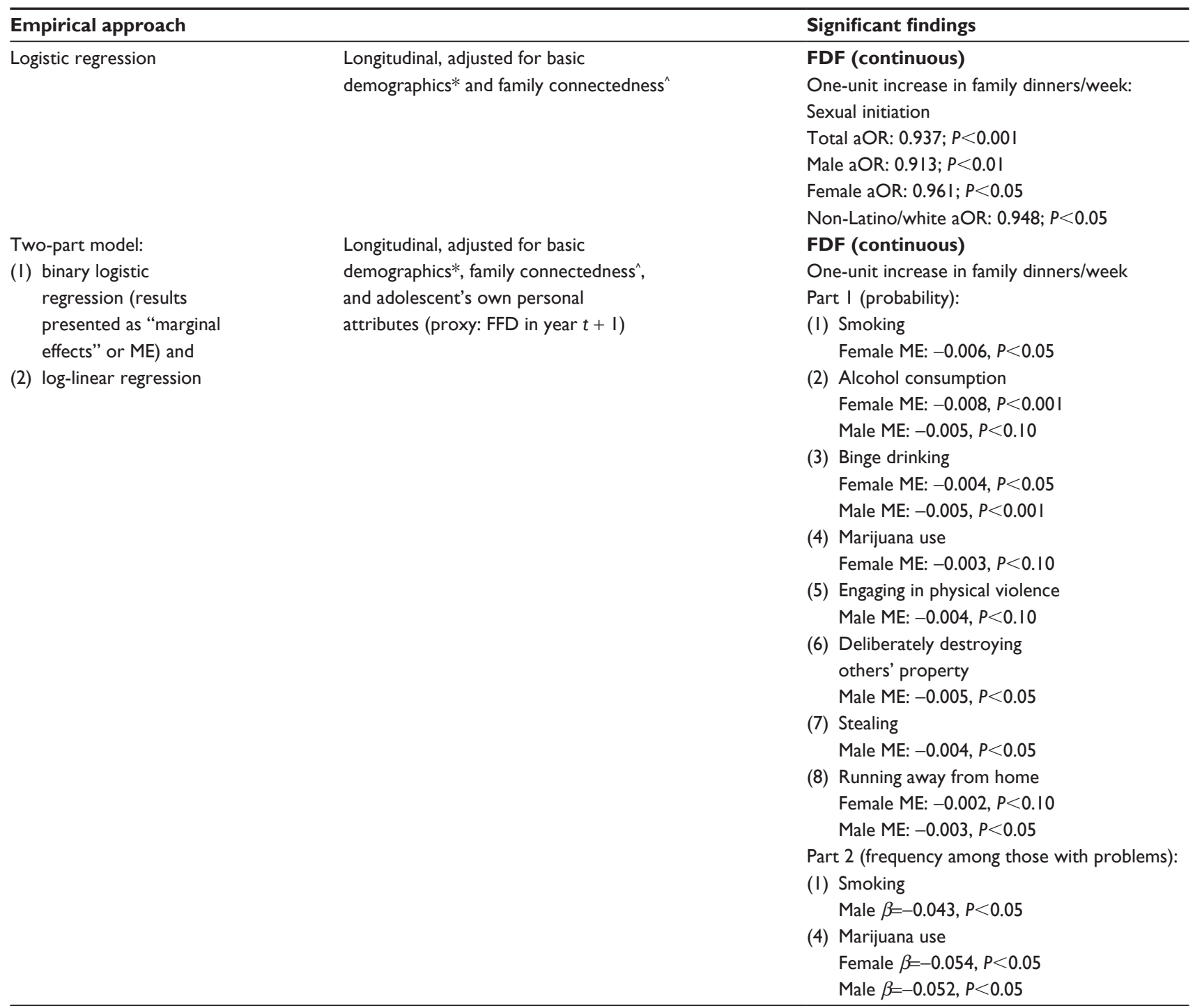




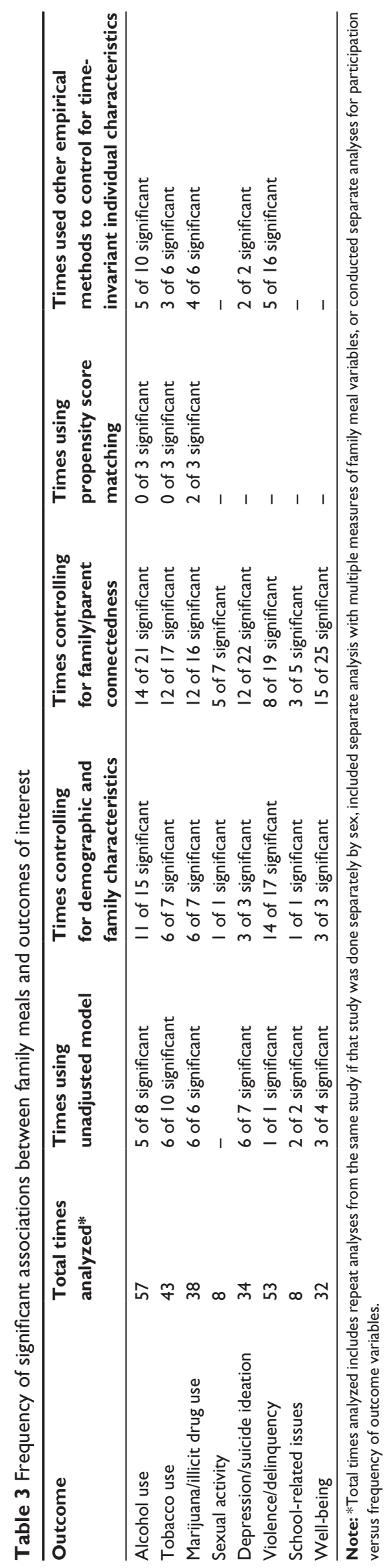

of data for the same adolescents. Thus, essentially, both Sen $^{10}$ and Musick and Meier ${ }^{8}$ used approaches that would account for the adolescent's unmeasured and time-invariant individual characteristics that could otherwise confound the relationship between FFM and the outcomes of interest.

Alcohol use was the outcome analyzed the largest number of times ( 57 times), followed by violence/delinquency (53 times), tobacco use (43 times), marijuana/illicit drug use (38 times), depression/suicide ideation (34 times), and well-being (32 times). Sexual activity and school-related issues were each analyzed only eight times. The associations between FFM and the outcome in question were most likely to be statistically significant with unadjusted models or univariate analyses. Associations were less likely to be significant in models that controlled for demographic and family characteristics or family/parental connectedness. When methods like propensity score matching were used, no significant associations were found between FFM and alcohol or tobacco use. When methods to control for timeinvariant individual characteristics were used, the associations were significant about half the time for substance use, five of 16 times for violence/delinquency, and two of two times for depression/suicide ideation. Notably, no analyses were identified that applied either propensity score matching or controlling for time-invariant individual characteristics to outcomes like sexual activity, school-related issues, and well-being.

\section{Discussion}

We reviewed 14 studies to examine the relationship between family meals and adolescent risk behaviors. The most commonly measured outcomes in this literature center on adolescent substance use, well-being, depression/suicide, and violence/delinquency. Many studies found significant associations between FFM and these categories; however, results differed by sex and also by the empirical approach used.

This review was conducted with a particular emphasis on the empirical methods used in the literature. The challenge is establishing plausible causal links between family meals and adolescent health outcomes. The most widely accepted scientific approach for establishing causality, randomized controlled trials, does not seem feasible in this research area, both because any "effects" of family meals on risky behaviors are unlikely to manifest themselves in the relative short run, and because of the ethical challenges inherent in a randomized controlled trial study design if it means that the "control group" will not be permitted to participate in family meals for the study period. However, there exists a 
rich array of other empirical methods that can be applied to infer causality plausibly, even with observational data. ${ }^{30,31} \mathrm{We}$ found that most analyses in this literature controlled for basic demographic and socioeconomic characteristics, sometimes also adding on other measures of family connectivity. Only a limited number of analyses used available empirical methods that help limit confounders like unmeasured individual-level characteristics. Moreover, there were no analyses using such approaches for outcomes like early sexual activity, schoolrelated issues, and well-being, and only two analyses using them for depression/suicide ideation.

Other potential empirical approaches that could be explored to minimize the effect of confounders include methods like sibling fixed effects, which have been applied to control for family-level confounders in areas like socioeconomic consequences of adolescent motherhood. ${ }^{32}$ Alternatively, researchers may also look for exogenous shocks that can influence the ability to eat together as families, and use the "instrumental variables" approach to control for confounders. ${ }^{33}$ Yet another approach, recently utilized in a study on breastfeeding and obesity, ${ }^{34}$ is randomizing families to treatment groups that are actively informed on the benefits of family meals versus control groups, and then using the randomization as an instrument.

Apart from utilizing the most sophisticated techniques available for addressing the problem of confounders in secondary data analysis, we argue that this field of research may also benefit by expanding the scope of risky adolescent behaviors considered. For example, the number of US high school adolescents who have ever tried "electronic cigarettes" or "e-cigarettes" has doubled from about one in 20 in 2011 to one in ten in $2012 .{ }^{35}$ While it is assumed that e-cigarettes come without the toxic effects of tobacco smoking, there is a general lack of research and understanding about the health risks. ${ }^{36-38}$ There are also other, well-established adolescent risk behaviors that have not been well explored in the context of family meals, such as risky driving behavior. It is well established that adolescents frequently engage in risky driving behaviors, such as riding in a car without a seat belt on, driving under the influence, or texting while driving. ${ }^{39-41}$ Given that the rate of fatal motor vehicle accidents is higher among teens than other age-groups, and that many teenagers involved in fatal car crashes have been found to have been engaged in risky driving behaviors, ${ }^{42}$ and given that eating together may provide an opportunity for parents to discuss these issues with their children, it is somewhat surprising that the family meal literature has not looked at the association between family meals and engaging in risky driving behaviors. Other adolescent risk-behavior outcomes worthy of further examination include abuse of prescription drugs, use of specific illicit drugs, intimate partner violence history, and specific problem behaviors in school (eg, school suspensions/expulsions, repeating a grade).

We acknowledge certain limitations in our study. Our search of the literature and selection of papers may be subject to human error. We are unable to consider whether there were other distractions accompanying family meals, such as television viewing. ${ }^{43}$ Finally, the lack of homogeneity both in how the outcomes are measured and how family meals are measured precluded doing a more rigorous meta-analysis. Nonetheless, this review provides a useful overview of the state of the literature, and clearly identifies the gaps both in terms of methods used and outcomes that are not considered or rarely considered. Given the importance of identifying factors that are truly protective for adolescents, further research is called for to address these gaps.

\section{Disclosure}

The authors report no conflicts of interest in this work.

\section{References}

1. Resnick MD, Bearman PS, Blum RW, et al. Protecting adolescents from harm. Findings from the National Longitudinal Study on Adolescent Health. JAMA. 1997;278(10):823-832.

2. Gibbs N, Miranda CA. The magic of the family meal. Time. 2006;167(24):50-56.

3. Hoffman J. The guilt-trip casserole: the family dinner. 2009. Available from: http://www.nytimes.com/2009/10/04/fashion/04dinner.html. Accessed September 24, 2013.

4. Council of Economic Advisers. Teens and their parents in the 21st century: an examination of trends in teen behavior and the role of parental involvement. 2000. Available from: http://clinton3.nara.gov/WH/EOP/ CEA/html/Teens_Paper_Final.pdf. Accessed September 23, 2013.

5. Eisenberg ME, Olson RE, Neumark-Sztainer D, Story M, Bearinger LH. Correlations between family meals and psychosocial well-being among adolescents. Arch Pediatr Adolesc Med. 2004;158(8):792-796.

6. Fulkerson JA, Kubik MY, Story M, Lytle L, Arcan C. Are there nutritional and other benefits associated with family meals among atrisk youth? J Adolesc Health. 2009;45(4):389-395.

7. Fulkerson JA, Story M, Mellin A, Leffert N, Neumark-Sztainer D, French SA. Family dinner meal frequency and adolescent development: relationships with developmental assets and high-risk behaviors. $J$ Adolesc Health. 2006;39(3):337-345.

8. Musick K, Meier A. Assessing causality and persistence in associations between family dinners and adolescent well-being. J Marriage Fam. 2012;74(3):476-493.

9. Eisenberg ME, Neumark-Sztainer D, Fulkerson JA, Story M. Family meals and substance use: is there a long-term protective association? JAdolesc Health. 2008;43(2):151-156.

10. Sen B. The relationship between frequency of family dinner and adolescent problem behaviors after adjusting for other family characteristics. J Adolesc. 2010;33(1):187-196.

11. National Center on Addiction and Substance Abuse at Columbia University. The importance of family dinners VIII: a CASAColumbia white paper. 2012. Available from: http://www.casacolumbia.org/upload /2012/2012924familydinnersVIII.pdf. Accessed September 23, 2013. 
12. Fisher LB, Miles IW, Austin SB, Camargo CA Jr, Colditz GA. Predictors of initiation of alcohol use among US adolescents: findings from a prospective cohort study. Arch Pediatr Adolesc Med. 2007;161(10): 959-966.

13. Griffin KW, Botvin GJ, Scheier LM, Diaz T, Miller NL. Parenting practices as predictors of substance use, delinquency, and aggression among urban minority youth: Moderating effects of family structure and gender. Psychol Addict Behav. 2000;14(2):174-184.

14. Fiese BH, Foley KP, Spagnola M. Routine and ritual elements in family mealtimes: contexts for child well-being and family identity. New Dir Child Adolesc Dev. 2006;2006(111):67-89.

15. Ochs E, Shohet M. The cultural structuring of mealtime socialization. New Dir Child Adolesc Dev. 2006;(111):35-49.

16. Neumark-Sztainer D, Hannan PJ, Story M, Croll J, Perry C. Family meal patterns: associations with sociodemographic characteristics and improved dietary intake among adolescents. $J$ Am Diet Assoc. 2003;103(3):317-322.

17. Berk LE. Infants, Children, and Adolescents. 6th ed. Boston: Allyn and Bacon; 2008.

18. Moher D, Liberati A, Tetzlaff J, Altman DG, Group P. Preferred Reporting Items for Systematic Reviews and Meta-Analyses: the PRISMA statement. PLoS Med. 2009;6(7):e1000097.

19. Varney S. French lessons: why letting kids drink at home isn't 'tres bien.' 2011. Available from: http://www.npr.org/blogs/ health/2011/12/12/143521104/french-lessons-why-letting-kids-drinkat-home-isn-t-tres-bien. Accessed October 31, 2013.

20. Cohen J. A coefficient of agreement for nominal scales. Educ Psychol Meas. 1960;20(1):37-46.

21. Viera AJ, Garrett JM. Understanding interobserver agreement: the kappa statistic. Fam Med. 2005;37(5):360-363.

22. GraphPad Software. QuickCalcs. 2013. Available from: http://graphpad. com/quickcalcs/kappa1. Accessed October 31, 2013.

23. Franko DL, Thompson D, Affenito SG, Barton BA, StriegelMoore RH. What mediates the relationship between family meals and adolescent health issues. Health Psychol. 2008;27(Suppl 2): S109-S117.

24. Griffin KW, Botvin GJ, Scheier LM, Diaz T, Miller NL. Parenting practices as predictors of substance use, delinquency, and aggression among urban minority youth: moderating effects of family structure and gender. Psychol Addict Behav. 2000;14(2):174-184.

25. Hoffmann JP, Warnick E. Do family dinners reduce the risk for early adolescent substance use? A propensity score analysis. $J$ Health Soc Behav. 2013;54(3):335-352.

26. Offer S. Assessing the relationship between family mealtime communication and adolescent emotional well-being using the experience sampling method. J Adolesc. 2013;36(3):577-585.

27. Offer S. Family time activities and adolescents' emotional well-being. J Marriage Fam. 2013;75(1):26-41.
28. Pearson J, Muller C, Frisco ML. Parental involvement, family structure, and adolescent sexual decision making. Sociol Perspect. 2006;49(1):67-90.

29. Fulkerson JA, Strauss J, Neumark-Sztainer D, Story M, Boutelle K. Correlates of psychosocial well-being among overweight adolescents: the role of the family. J Consult Clin Psychol. 2007;75(1):181-186.

30. Heckman JJ. Econometric causality. Int Stat Rev. 2008;76(1):1-27.

31. Antonakis J, Bendahan S, Jacquart P, Lalive R. On making causal claims: a review and recommendations. Leadersh Q. 2010;21(6): $1086-1120$

32. Geronimus AT, Korenman S. The socioeconomic consequences of teen childbearing reconsidered. Q J Econ. 1992;107(4):1187-1214.

33. Newhouse JP, McClellan M. Econometrics in outcomes research: the use of instrumental variables. Annu Rev Public Health. 1998;19(1): $17-34$.

34. Martin RM, Patel R, Kramer MS, et al. Effects of promoting longerterm and exclusive breastfeeding on adiposity and insulin-like growth factor-I at age 11.5 years: a randomized trial. JAMA. 2013;309(10): $1005-1013$.

35. Centers for Disease Control and Prevention. E-cigarette use more than doubles among US middle and high school students from 2011-2012 [press release]. Atlanta: CDC; 2013 [September 5]. Available from: http://www.cdc.gov/media/releases/2013/p0905-ecigarette-use.html. Accessed September 25, 2013.

36. Goniewicz ML, Zielinska-Danch W. Electronic cigarette use among teenagers and young adults in Poland. Pediatrics. 2012;130(4): e879-e885.

37. Choi K, Forster J. Characteristics associated with awareness, perceptions, and use of electronic nicotine delivery systems among young US Midwestern adults. Am J Public Health. 2013;103(3): 556-561.

38. Pearson JL, Richardson A, Niaura RS, Vallone DM, Abrams DB. e-Cigarette awareness, use, and harm perceptions in US adults. Am J Public Health. 2012;102(9):1758-1766.

39. Sen B, Patidar N, Thomas S. A silver lining to higher prices at the pump? Gasoline prices and teen driving behaviors. Am J Health Promot. Epub April 26, 2013.

40. Carpenter CS, Stehr M. The effects of mandatory seatbelt laws on seatbelt use, motor vehicle fatalities, and crash-related injuries among youths. J Health Econ. 2008;27(3):642-662.

41. Williams A, Wells J, Lund A. Seat Belt Use among High School Students. Washington: National Highway Traffic Safety Administration; 1982.

42. National Highway Traffic Safety Administration. Traffic Safety Facts 2008. Washington: US Department of Transportation; 2008.

43. Eisenberg ME, Neumark-Sztainer D, Feldman S. Does TV viewing during family meals make a difference in adolescent substance use? Prev Med. 2009;48(6):585-587.
Psychology Research and Behavior Management

\section{Publish your work in this journal}

Psychology Research and Behavior Management is an international, peerreviewed, open access journal focusing on the science of psychology and its application in behavior management to develop improved outcomes in the clinical, educational, sports and business arenas. Specific topics covered include: Neuroscience, memory \& decision making; Behavior

\section{Dovepress}

modification \& management; Clinical applications; Business \& sports performance management; Social and developmental studies; Animal studies. The manuscript management system is completely online and includes a quick and fair peer-review system. Visit http://www.dovepress. com/testimonials.php to read real quotes from published authors. 